\title{
La poesía argentina en la década de 1930: Un problema historiográfico
}

The Argentinan poetry in the 30s decade: A historiographic problem

Aníbal Salazar Anglada

Universitat Ramon Llull. España

anibalsa@blanquerna.url.edu

\section{RESUMEN}

El presente trabajo aborda desde una perspectiva crítica una de las parcelas más controvertidas de la historiografía referida a la poesía argentina moderna: la llamada "generación de 1930", los novísimos, quienes toman su nombre de la antología titulada La novísima poesía argentina (1930). Su compilador, Arturo Cambours Ocampo, se erige en mentor (e inventor) de una generación poética, la del 30, cuya tentativa de instalarse en la historia literaria nacional va a suscitar una ardua polémica en los medios críticos.

Palabras claves: Poesía, Argentina, Generación de 1930, Arturo Cambours Ocampo, novisimos, historiografía, antologías, canon.

\section{ABSTRACT}

This paper is a critical study from one of the most controversial topics in the historiography of modern Argentinan poetry: "La generación de 1930", known as the novisimos. They took their name from the anthology entitled La novísima poesía argentina (1930). The compiler is called Arturo Cambours Ocampo, which he is the mentor and inventor of "La generación de 1930". Ocampos temptative of installing himself in the national literary history, will generate a great controversy in the literary criticism. 
Keywords: Poetry, Argentina, Generación de 1930, Arturo Cambours Ocampo, Novisimos, historiography, anthologies, canon.

Recibido: 05-12-2008. Aceptado: 04-01-2009.

\title{
LOS OLVIDADOS AÑOS 30 EN LA POESÍA ARGENTINA
}

\begin{abstract}
A comienzos de los años 80, Carlos Giordano publicaba en Revista - Uberoamericana un artículo titulado "Entre el 40 y el 50 en la poesía argentina”, en el que ponía de relieve la problemática que plantean tales años desde una clasificación historiográfica (Giordano, 1983). Sobre todo teniendo en cuenta las limitaciones del método generacional aplicado a la literatura, los vicios terminológicos que ha venido engendrando y la consecuente e irremediable reducción de lo múltiple y diverso a una imagen grupal uniforme. "El método histórico de las generaciones ha sido aplicado con sorprendente entusiasmo por muchos de los historiadores y antólogos de la literatura argentina (...), pero con resultados que, a mi juicio, no compensan" (Giordano, 1983: 786). La reflexión de Giordano es interesante por cuanto menciona dos hechos a tener en cuenta: de un lado, el poco celo por parte de la crítica nacional a la hora de establecer una serie de generaciones literarias tan prolongada como excesiva; y de otro lado, el papel que juegan las antologías en la nomenclatura generacional, parejo al de las historias literarias. Nos recuerda Graciela Montaldo (1989: 40) que las antologías son una tradición de la historia literaria, en el sentido en que las compilaciones poéticas anteceden en Hispanoamérica al surgimiento de las primeras historias de la literatura. Uno y otro constructo, historia y antología, marcan a la postre el establecimiento de un canon de cultura que es expresión de la identidad colectiva ${ }^{1}$.

El artículo de Giordano ponía su mayor atención en el tránsito de la realidad poética del $40 \mathrm{al} 50$, dejando en un segundo plano en cambio uno de los periodos más ignorados y controvertidos de la poesía argentina moderna: los años 30 . Se advierte un fuerte contraste entre la sobreabundancia bibliográfica en torno a la vanguardia de los 20, sobre la que puntualmente se publican monografías, y el erial que muestra la crítica en torno a la década de 1930, pese a que la producción poética va a seguir siendo muy abundante en la Argentina. Tal hecho dificulta el abordaje de estos años, necesitados de aportes esenciales sobre

${ }^{1} \mathrm{Al}$ respecto extraigo algunas de las apreciaciones referidas a la poesía argentina de los años 30 del capítulo quinto de mi libro La poesía argentina en sus antologías, 1900-1950. Una reflexión sobre el canon nacional (Salazar Anglada, 2009).
\end{abstract}


la base de lo realizado. Es cierto que por entonces cobra un importante auge la narrativa argentina, y en general la que inicia su andadura en el continente americano toda vez que empieza a notarse la influencia de la novela europea de vanguardia, al tiempo que pervive la ya muy explotada (y exportada) novela social proveniente de Rusia. De modo que junto a los prosistas argentinos que realizan una obra de tinte social y político (Elías Castelnuovo, Lorenzo Stanchina, González Tuñón, Roberto Arlt) encontramos una serie de escritores que emprenden un camino más esteticista y también más cercano a cuestiones metafísicas (Borges, Norah Lange, Silvina Ocampo, Eduardo Mallea). Algo más tarde se dan a conocer, dentro de la línea del fantástico, José Bianco y un joven Adolfo Bioy Casares que en 1940 publica su novela más aplaudida, $\mathrm{La}$ invención de Morel. Por estos mismos años se dan a conocer Ernesto Sábato, Mujica Láinez, Manuel Peyrou, entre otros narradores de primer orden. Muy posiblemente este auge de la narrativa ha perjudicado la atención prestada a la poesía de esta década, estudiada de forma puntual a través de obras y autores específicos, y no tanto desde una mirada global que muestre los itinerarios y avatares históricos.

En otro orden de cosas, si atendemos a la perspectiva socio-política y económica del país la década del 30 se muestra compleja desde sus comienzos, marcados por el golpe de Estado del 6 de septiembre de 1930 que llevan a efecto algunos mandos del Colegio Militar encabezados por el general José Félix Uriburu. Este hecho va a marcar fatídicamente el rumbo de la vida política y sociocultural de la República durante más de medio siglo (desde 1930 hasta entrados los 80), un periodo que constituye sin duda la etapa más desconcertante, antidemocrática y sangrienta de la historia moderna del país, de la que aún restan muchas heridas por cerrar.

No obstante la orientación constitucionalista que el gobierno golpista quiere imprimir a sus actos, algunos hechos visibles demuestran el verdadero signo dictatorial del movimiento insurrecto. Un caso llamativo es el que representa el diario vespertino Crítica, cuyo director, el uruguayo Natalio Botana, declarado antifascista, se posiciona abiertamente en contra de la insurgencia revolucionaria. Como consecuencia de ello la esposa de Botana, la escritora Salvadora Medina Onrubia, antigua anarquista, fue enviada a prisión, como otros tantos intelectuales disidentes. Este hecho provocó la movilización de un nutrido grupo de escritores, algunos de ellos colaboradores del periódico, quienes en tono conciliatorio hacen llegar a Uriburu a través de las páginas de El Diario una carta en favor de Medina Onrubia. Entre los firmantes se cuentan Arturo Capdevila, Alfonsina Storni, Horacio Quiroga, Alberto Gerchunoff, Eduardo Mallea, Jorge Luis Borges, Cayetano Córdova Iturburu, 
Nydia Lamarque. Finalmente, tras una misiva mucho más contundente enviada a Uriburu por la propia Medina Onrubia desde la cárcel, tanto ella como su marido son deportados a Montevideo, con la consecuente clausura del periódico (Saitta, 1998: 247 y ss.). Otro de los hechos que muestran la verdadera naturaleza del gobierno de Uriburu es la intervención de la Universidad de Buenos Aires, dada la pérdida del control de la Facultad de Derecho por parte de las fuerzas conservadoras; una decisión que habría de provocar el rechazo de los movimientos estudiantiles. No menos significativa e inquietante resulta la creación de la Legión Cívica, cuerpo militar de apoyo a las Fuerzas Armadas cuya misión principal consiste en velar por el cumplimiento de los anhelos nacionales expresados en el programa de la Revolución.

\section{EL PROBLEMA DE LAS GENERACIONES LITERARIAS. ESBOZOS PARA UN ESQUEMA DE LA POESÍA ARGENTINA MODERNA}

Como es sabido, la nota dominante desde la perspectiva de la historia literaria es la búsqueda de un modelo teórico capaz de explicar el modo en que evolucionan las ideas estéticas. Un modelo apto para parcelar el continuum de la actividad literaria en periodos de tiempo delimitados por hechos significativos, a veces en relación directa con la realidad socio-política nacional, otras en relación a ciertos hitos culturales. Uno de los modelos preponderantes y más recurrentes, procedente de la Europa central, lo constituye el método generacional, llevado primero al terreno de la historia por el pensamiento moderno alemán y orientado con posterioridad hacia los estudios literarios ${ }^{2}$.

En Hispanoamérica, dos de las más tempranas aplicaciones del método a la historia literaria continental son las que llevan a cabo José Antonio Portuondo en un artículo de 1948 titulado "Períodos y Generaciones en la historiografía literaria hispanoamericana”; y José Juan Arrom, quien desarrolla un Esquema generacional de las letras hispanoamericanas (1963). Por lo que concierne al ámbito de los estudios nacionales, la aplicación de esta metodología comienza a extenderse a comienzos de los años 40. En ocasiones la formulación de la teoría generacional

\footnotetext{
${ }^{2}$ Por cuanto se refiere a esta última aplicación, debe señalarse la influencia de Julius Petersen (1930) a través de su ensayo "Die Literarischen Generationen”. En el medio cultural hispánico van a ser tenidas en cuenta fundamentalmente las aportaciones de Ortega y Gasset, cuyos planteamientos enraízan de lleno en la historia (al hablar de "generación", Ortega se refería a la sociedad entera y no a una parcela de la misma como es la artístico-literaria), junto con las ideas de Petersen, quien deriva de forma más concreta hacia la historia literaria. Otras influencias notables más allá de estas mencionadas son las de Albert Thibaudet y su Histoire de la littérature francaise de 1789 à nos jours (1936), y Julián Marías - uno de los discípulos dilectos de Ortega- a través de su conocido ensayo El método histórico de las generaciones (1949).
} 
resulta de la síntesis de Petersen y Ortega, pues en el fondo los postulados de ambos se complementan. Ocurre así en el caso concreto de César Fernández Moreno, punta de lanza y gran adalid del método de las generaciones literarias en el medio argentino, quien participa además en una de las historias literarias nacionales más reputadas, la Historia de la literatura argentina de Rafael A. Arrieta (1958-1960). Son varios los textos en que Fernández Moreno dedica sus esfuerzos críticos al establecimiento de una periodología generacional referida a la poesía. Así, en su capítulo sobre la poesía de vanguardia incluido en la Historia de Arrieta (Fernández Moreno, 1959: 605-669), el escritor comienza por aclarar la metodología a través de la cual va a acercarse a la materia de estudio y señala como sus fuentes más directas a Ortega y Gasset y Petersen. También en su conocido libro $L$ a realidad y los papeles encontramos apreciaciones harto sugerentes respecto al tema en cuestión (Fernández Moreno, 1967: 31 y ss.). Muy anterior a los dos textos citados es el "Informe sobre la nueva poesía argentina" que Fernández Moreno (1943) publica en Nosotros, donde adelanta algunas consideraciones de interés acerca del concepto de generación literaria que desarrollará en sus ulteriores trabajos (71-93).

Fernández Moreno (1967) advierte en sus escritos un hecho que no en vano es el eje vertebrador del presente trabajo, a saber: el titubeo que, en su afán de periodización, muestra la historia literaria nacional a partir de la disolución de la primera sacudida de vanguardia hacia el final de los años 20:

Es clara y definida ya por estudios de suficiente seriedad la estructura de las dos generaciones (modernista e intermedia) que preceden a la primera vanguardia (ultraísta), y aun ésta ha sido debidamente reconocida y declarada independiente. El esquema se torna un tanto confuso cuando llegamos a la segunda generación vanguardista (neorromántica). Surgen al respecto opiniones contradictorias acerca de la disposición generacional de esta nueva promoción y sus relaciones con la inmediata anterior (Fernández Moreno, 1967: 223-224).

Cabe insistir en que no se trata de valoraciones unánimes, como tampoco hay un acuerdo común acerca de las denominaciones. Los hay quienes, por ejemplo, tratan de sortear la cuestión de las décadas 1940-1950 proponiendo una "generación del 45" como solución intermedia; e incluso se duda de la existencia misma de algunas de las generaciones que proponen los historiadores, como es el caso paradigmático de la "generación del 30", la de los poetas novísimos, puesta en tela de juicio a lo largo de un intenso debate que se prolonga durante varios lustros. 
Llegados a este punto, convendría examinar someramente el modo (o los modos) en que se plantea desde la historia literaria nacional la evolución de la poesía argentina en las cuatro primeras décadas del siglo XX. Este tipo de examen nos induce sin más remedio a hablar de la debatida cuestión, aunque comúnmente aceptada en tiempos, en torno a las generaciones literarias. La influencia de Ortega y Gasset en el implante y desarrollo de dicho modelo, primero en los estudios históricos y más tarde en el medio literario, va a ser crucial, como he dicho. De forma muy especial, Argentina es uno de los países donde mayormente repercuten sus ideas, que se dejan notar hacia los años 20-30, y aún más en las décadas que siguen (Aguilar et al., 1997). Pero hablamos, qué duda cabe, de un fenómeno global que afecta por igual a todas aquellas naciones hispanoamericanas que hacia la década de 1950 han desarrollado una cierta conciencia crítica respecto al propio proceso cultural. En su conocido ensayo sobre las generaciones literarias en Cuba, el crítico e historiador Raimundo Lazo se interroga acerca de quién hace la historia, quién la dota de corporeidad y movimiento. A lo que responde sin dudarlo: la teoría de las generaciones literarias. Pues a través de ésta, nos dice, lo colectivo se hace presente en la historia (Lazo, 1954: 6).

En el citado "Informe" de 1943, Fernández Moreno advierte ya que el término "generación" se ha convertido en "una palabra tan gastada como imprecisa" (1943: 83). Es por ello que antes de llevar a cabo su aplicación a la realidad poética en Argentina trata de precisar a nivel técnico el significado de tal término en el ámbito de la historia literaria.

El diccionario de la Academia define el vocablo generación, en la acepción que nos interesa, como "el conjunto de todos los vivientes coetáneos". Y por coetáneos entiende a las "personas que viven o coinciden en una misma edad o tiempo". El criterio que surge de estas definiciones es, sin duda, demasiado lato para juzgar una generación literaria. En primer lugar, hay que limitar el concepto de coetáneos a los que hayan nacido dentro de un determinado período: diez o quince años. Pero, ¿qué punto de partida dentro de la sucesión del tiempo deben tener esos diez o quince años? Aquí entra un nuevo elemento, aún no considerado: la obra de la generación, el hecho de haberse dedicado los mejores hombres nacidos en una misma época a una actividad convergente, y haber logrado éxito destacado en ella. Una generación muy prominente, pues, sirve de hito cronológico a las siguientes (Fernández Moreno, 1943: 83).

Desde estos presupuestos y atendiendo a la repercusión de unas generaciones sobre otras, Fernández Moreno (1943) señala dos etapas diferenciadas que pueden darse en la evolución de toda generación literaria, a saber: 
a) La generación en sus principios. Un núcleo de personas jóvenes necesita desplazar hacia sí el foco de la atención social, dirigido hacia el núcleo anterior, al cual la nueva promoción considera inferior o simplemente extemporáneo, en decadencia o no. Se entabla de inmediato una lucha por la posesión de los medios de expresión: en nuestro caso, tribunas, editoriales, librerías, revistas y suplementos literarios. A este efecto, los jóvenes se suelen unir, olvidando sus divergencias estéticas, pues se trata, ni más ni menos, de una lucha de supervivencia. Una vez conquistado el medio social, la atención del público, se acaba la lucha, que era el aglutinante inmediato de estos esfuerzos dispersos. A esta altura de las cosas, la entidad colectiva generación puede desaparecer o sobrevivir. Desaparece, si su cohesión se debía exclusivamente a la necesidad de la lucha. En este caso, su papel habrá sido meramente accidental, temporal. (...)

b) Pero la generación sobrevive, si los lazos que la unían eran más profundos: éticos, políticos, estéticos. En este caso, los hombres que la integraban pueden abandonar el contacto directo con sus compañeros de lucha y variar de radicación en el espacio, con la seguridad de que aquello que escriba o produzca cada uno de ellos será homólogo, concordante, paralelo (84).

Respecto a la lucha entre generaciones que en un mismo tiempo entran en conflicto, Juan Pinto pone de relieve el carácter subversivo que ha de caracterizar a toda "generación" que se precie de serlo, la cual debe dirigir sus pasos a contracorriente de lo establecido normativamente:

Cuando los coetáneos aceptan las condiciones dadas históricamente, la generación no existe como fuerza renovadora; se limita a ser un hecho vegetativo de la historia. Pero cuando la generación reacciona contra las condiciones dadas -a veces lo hace aferrándose a viejas ideas inyectándoles nuevo vigorhaciéndose combativa, es decir cuando trata de imponer sus puntos de vista y desplazar la generación que le precede, la generación adquiere sentido histórico, es, convirtiéndose en el punto de partida de un movimiento o de un modo de pensar, sentir y ver que actúa, no solamente en su tiempo, sino que se proyecta en la generación siguiente (Pinto, 1958: 11).

A diferencia de Fernández Moreno, algunos críticos e historiadores de la literatura argentina han optado por una adaptación de las tesis de Ortega y Petersen a partir de un aprovechamiento parcial o fragmentario de las mismas, o bien tomando de un modo más relajado los criterios de evaluación que uno y otro autor marcan a la hora de considerar la existencia de una generación. 
Anderson Imbert destaca en su Historia de la literatura hispanoamericana, y no precisamente como un hecho del todo positivo, la fuerte influencia ejercida por Ortega y su idea de la "sensibilidad vital" que determina cada generación. Al cuestionar la existencia de una generación poética de 1930 en Argentina, el crítico e historiador comenta en tono irónico:

¿Generación del Centenario de Independencia? ¿Generación de la visita del cometa Halley? El acontecimiento, histórico o sideral, era lo de menos. Lo que importaba era ser generación, novísima generación. Y el prurito fue tal que desde entonces no se ha cesado de inventar generaciones: del 40, del 45, del 50, del 55. Más generaciones de las que humanamente pueden caber en lapso tan corto (Anderson Imbert, 1961: 146-147).

Atendiendo a este fenómeno de las generaciones literarias y su rápida proliferación, Emilio Carilla (1989) dictamina: "Una cosa -pienso- es recurrir a tales métodos con la posibilidad de obtener de ellos algunas ventajas sobre los métodos tradicionales (épocas, estilos, escuelas, géneros, etc.), y otra, muy distinta, atribuirles poderes mágicos, o simplemente sospechar que la ubicación general de un autor o una obra resuelve todos los problemas literarios" (116). En su opinión, la utilidad de los métodos generacionales que han sido llevados a la práctica radica en "la necesidad orientadora del agrupamiento, de reunir y ordenar un material vasto (vastísimo) que siempre corre peligro de diluirse en lo caótico" (116). El secreto, apunta unas páginas más adelante, está en no exigir a dichos métodos más de lo que pueden dar, "en considerarlos fundamentalmente, como una línea de inserción y un punto de partida, y en no pretender cuadros cerrados y absolutos" (124).

Hoy día el método generacional está en parte superado, y no sólo esta clase de método sino otros afines a la periodología, que demuestra ser un constructo frágil, aún más si tenemos en cuenta el cuestionamiento que sufre el concepto mismo de "historia" en el periodo cultural que se ha dado en llamar posmodernidad. Frente a aquellos historiadores de la literatura argentina que han seguido apostando por el método generacional en cualquiera de sus variantes, con mayor o menor rigidez, hay quienes afirman la inutilidad de tal metodología en la medida en que enturbia la verdadera realidad de los hechos y sus particularidades. "Yo no creo en la utilidad del método histórico de las generaciones -afirma Giordano de modo taxativo- y prefiero manejarme con las categorías de estilo, tendencia, movimiento, escuela o grupo, según convenga" (1983: 786). 


\section{EN TORNO A UNA PRESUNTA GENERACIÓN POÉTICA DEL 30.} ¿UNA INVENCIÓN HISTORIOGRÁFICA?

Comparada con la década inmediata anterior, la poesía argentina de los años 30 plantea un problema mayor más allá de la mera discusión en torno a su nomenclatura adecuada. Al exponer la problemática de un modo general, podría decirse que la década de 1930 muestra un enorme vacío desde una perspectiva crítica, como se dijo al inicio. Las historias literarias, tanto las propiamente argentinas como las continentales, y de forma generalizada los esbozos generacionales que he podido consultar, niegan por lo común la existencia de una generación poética del 30 . De tal forma, sucede que lo más habitual es pasar de la generación de 1922 (también denominada de 1924 e incluso 1925) a la generación neorromántica de 1940, que sí ha tenido una aceptación por parte de críticos e historiadores, y de la que existen algunos aportes bibliográficos de consideración. En su asedio a la poesía del 40, Giordano señala como generación inmediatamente anterior a este periodo el movimiento poético que se inicia en torno a 1922, "el primer movimiento de vanguardia en la Argentina" (Giordano, 1983: 784-785). Del mismo modo ocurre en el esquema generacional que realiza Carilla, quien propone la siguiente serie de diez generaciones literarias: 1810, 1821, 1837, 1853, 1866, 1880, 1896, 1910, 1924, 1940, 1955, 1968 (Carilla, 1989: 112-113). Aunque no de un modo riguroso, es palpable que Carilla se deja guiar por el criterio de distancia temporal entre una generación y la que le sigue, exigencia que Ortega y Gasset cifra, recordemos, en no menos de 15 años, lo que a todas luces imposibilita que después de la generación de 1924 pueda señalarse otra hacia 1930.

Frente a un importante sector de la crítica contemporánea, el escritor Arturo Cambours Ocampo se erige en máximo defensor de la promoción poética del 30, a la que denomina "novísima generación", siendo él mismo uno de los integrantes del grupo. Su antología de 1931, La novisima poesía argentina, no es sino un intento de catapultar la mencionada generación y afianzarla en la historia literaria nacional. Junto a Cambours Ocampo, otro de los críticos que defiende la existencia de tal generación es Horacio Salas (1968), quien incluye en su antología crítica La poesía de Buenos Aires el siguiente epígrafe: "1930: aparece una nueva generación". Bajo este enunciado se nos hace saber que: "Al año de producirse la revolución de septiembre de 1930, que transformó la estructura política del país, un grupo de escritores jóvenes capitaneados por Arturo Cambours Ocampo publica, con el auspicio de la revista Letras [...], una antología de La novísima poesía argentina. El grupo se lanza contra la generación anterior y para demostrar los valores de los que surgen, realiza 
un extenso muestrario poético" (Salas, 1968: 43). Teniendo en cuenta la temática que preside la obra de Salas (en torno a la ciudad de Buenos Aires y sus posibilidades poéticas) y teniendo en cuenta además el modo en que el antólogo organiza la obra (a saber, en capítulos que corresponden a generaciones poéticas), es evidente que le conviene presentar a los llamados novísimos como una realidad existente y cohesionada, dado que en la poesía de aquéllos "el tema de la ciudad aparece con marcada insistencia y una tónica característica”, en palabras de Salas (1968: 43).

Una de las escasas monografías que aborda la poesía del 30 desde la perspectiva generacional es el estudio-antología publicado por la investigadora Lidia F. Lewkowicz bajo el título Generación poética del 30 (1974). En la "Introducción", la autora justifica de inicio la existencia de la generación poética de los novisimos, en línea con la defensa desarrollada por Cambours Ocampo, y examina la filosofía ética y estética que la caracteriza, así como los temas que desarrolla y las revistas más afines a través de las que se difunde su poesía.

El objetivo perseguido -en lo posible- es documentar y reconstruir las actividades de la generación literaria de 1930 o Novísima Generación; en consecuencia, será necesario consignar algunas particularidades a través de las cuales se presiente por qué nació dicha promoción, cuáles fueron sus momentos culminantes y cuáles los extremos; esta determinación permitirá entretejer la imagen y ponderar la medida en que sus manifestaciones consignaron un jalón dentro de la literatura nacional (Lewkowicz, 1974: 10).

\section{LA NOVÍSIMA POESÍA ARGENTINA (1931) DE CAMBOURS OCAMPO. UNA ANTOLOGÍA POLÉMICA}

De entre los trabajos antológicos publicados en la década de 1930, es La novisima poesía argentina de Cambours Ocampo (1931) el que presenta un mayor interés para la historia literaria argentina de la primera mitad del siglo XX, en tanto que plantea un debate generacional que en el grado de personalización alcanza la intensidad de un fuego cruzado. La obra fue publicada por la editorial Letras, revista de principios de los años 30 que dirige el propio Cambours Ocampo, quien por este mismo entonces lleva

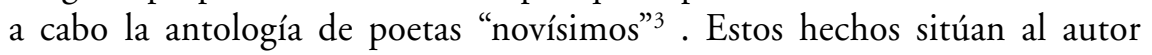

${ }^{3}$ Por lo que se refiere a la citada revista, en la primera época de Letras (núms. 1-14), que abarca desde su fundación en 1930 hasta abril de 1933, formaban parte de la redacción los escritores Arturo Cerretani, Carlos A. Barry, Teófilo Hiroux Funes, José Luis Lanuza, Eliseo Montaine, Edmundo 
como verdadero impulsor del grupo a través de dos instrumentos críticodivulgativos: una revista y una antología.

En unas palabras pertenecientes a la "Aclaración" con que se abre la antología, Cambours Ocampo (1963) aboga por un revisionismo literario que ha de trascender la crítica del pasado -ese eterno "escribir sobre las tumbas" para abordar el estudio de las últimas generaciones, las más actuales, llegando a abarcar incluso la obra inédita de los autores noveles. Es lo que el escritor denominaría años después "literatura crítica de anticipaciones" (Cambours Ocampo, 1963: 7). Este planteamiento expresado en los años 60 es el mismo que determina y acota su antología de 1931 al centrar su atención en una novísima generación de escritores. Dicho marbete debe ponerse en relación directa con la designación de la anterior generación: la "nueva generación" o "nueva sensibilidad", que no se refiere a otra cosa que a la primera generación de vanguardia. Con objeto de distinguir y privilegiar su propia labor, no sólo como antólogo del grupo sino como miembro activista del mismo, el autor de La novísima poesía sitúa esta compilación en un primer plano de renovación al mostrar una obra (la de los autores seleccionados) en proceso, abierta, por tanto inacabada. Y es precisamente este aspecto el que, según él, distingue su trabajo de los anteriores volúmenes antológicos.

Cambours Ocampo será uno de los críticos que desarrolle mayormente en sus investigaciones el método generacional. En 1949 imparte en la Facultad de Humanidades de la Universidad Nacional de La Plata un curso sobre las generaciones literarias argentinas, aplicando por primera vez de forma rigurosa y sistemática los planteamientos historicistas de Petersen. Algunas de las apreciaciones apuntadas cobran desarrollo posteriormente en dos importantes obras: Indagaciones sobre literatura argentina (1952) y Lugones. El escritor y

Luján Benítez, Antonio Miguel Podestá, Jacobo de Diego y Rodolfo Zavalía Matienzo, algunos de los cuales se hallan recogidos en La novísima poesía argentina. En septiembre de 1933 se inaugura la segunda época, con Cerretani al frente de la revista. Esta otra etapa consta de un solo número, que por cierto polemiza con otra revista importante del momento, Megáfono, en torno a un especial monográfico dedicado a Borges. A través de Letras, que muy pronto crea su propia editorial, ven la luz las primeras obras de algunos de los jóvenes componentes de la generación del 30, como es el caso de José Luis Lanuza, Arturo Cerretani o Juan Óscar Ponferrada. De este modo, y pese a su irregularidad, Letras se convierte en el órgano difusor de la obra de los novísimos, la tribuna desde la cual éstos expresan los ideales estéticos del grupo.

${ }^{4} \mathrm{La}$ frase está tomada de un ensayo publicado a principios de los 60, donde Cambours Ocampo señala: "Los argentinos estamos acostumbrados a escribir sobre las tumbas; a esperar que la muerte entregue sus fichas amarillas, como una contraseña de la impunidad crítica; a no plantear el aquí y el ahora; a olvidarnos del presente y del futuro, por comodidad y cobardía" (Cambours Ocampo, 1963: 7). 
su lenguaje (1957). En la primera de ellas se trazan las generaciones literarias argentinas desde el inicio del proceso de Independencia hasta la generación de 1930, quedando establecidas un total de seis, a saber: 1810 ("nuestra independencia política”); 1830 (“romántica y política”); 1880 (“progreso de nuestro país"); 1907 ("Rubén Darío y el modernismo"); 1922 ("la del periódico Martín Fierro"); y 1930 ("a la que pertenecemos", señala el escritor). Resulta cuando menos curiosa la asociación del año 1907 con "Rubén Darío y el modernismo", siendo como es esa fecha indicativa de uno de los acontecimientos más relevantes de la poesía moderna argentina: el nacimiento de la revista Nosotros, en torno a la cual se desarrolla una generación de escritores que va a marcar el rumbo de la cultural nacional, amén de dar cabida a las nuevas estéticas que se suceden desde comienzos de la década de 1920. Más bien lo que tiene lugar alrededor de 1907 es herencia directa del modernismo rubendariano, toda vez que se atenúan los excesos decadentistas y se reorientan los temas hacia la realidad propia.

La última de las generaciones poéticas señaladas, la del 30, es aquella a la que Cambours Ocampo denominaba ya en 1931 la "novísima generación", cuyo germen está en los círculos universitarios de la capital. Es en el seno de esta institución educativa, pero instrumentalmente política, donde se está redefiniendo por entonces el concepto de "intelectual" y su cometido en el medio social y cultural argentino, en un intento de exterminar los estereotipos decimonónicos del "gentleman" burgués y del "bohemio" iluminado.

En el mismo año en que se da a conocer la antología, el crítico literario y polemista Ramón Doll (1931) plantea de un modo positivo la existencia de tal generación, a la que elogia fundamentalmente porque no muestra ningún rol político maniqueísta impuesto por la hora -ni marxista, ni fascista, ni izquierdista ni derechista-, y también porque su aparente conformismo en el fondo no es sino una forma de escepticismo crítico frente a la realidad nacional en cualquiera de sus ámbitos (Doll, 1931: 13). Lo que en palabras de Cambours Ocampo (1931) debería definir a la generación poética del 30 es el pacifismo en el terreno de las artes: "Nuestra filosofía estética debe ser pacífica" (7). El calificativo "pacifista" aplicado a la realidad cultural se basa en una distinción hecha por Ortega y Gasset entre "generaciones beligerantes" y "generaciones pacifistas". El antólogo hace hincapié en el significado de tal distinción dentro del contexto de la cultura propia, queriendo con ello disipar cualquier posible malentendido:

No sé si Ortega y Gasset, al hablar de las generaciones beligerantes y pacifistas, trataba de hacerlo en el sentido integral, abarcando todas las actividades; por mi parte, si adopté la fórmula del filósofo hispano, fue para limitarme dentro del terreno puramente estético -véase que no digo literario- y para explicar 
una situación local, un fenómeno nuestro, desconectando por un momento la novísima generación del enchufe mundial (Cambours Ocampo, 1931: 7).

Tal actitud muy posiblemente actúa como contrafuerte ante una circunstancia socio-política minada de turbulencias tras los sucesos funestos de la revolución de septiembre de 1930, cuando la ley marcial impuesta por el alto mando del ejército pone en cautela los derechos constitucionales. Pese a todo, uno de los máximos ideólogos de la generación del 30, Arturo Cerretani, afirma rotundamente que el movimiento encabezado por los novísimos se produjo de forma espontánea, "sin que nada ni nadie motivasen su advenimiento"s.

En su crítica de La novisima poesía argentina, Augusto González Castro (1966) juzga el talante conciliador promulgado por Cambours Ocampo como un error del todo inoportuno, teniendo en cuenta que se trata de una muestra de la más joven poesía argentina, y que por tanto debería rezumar los valores propios de la juventud: "Debo formularle algunos reparos a esta obra de muchachos que salen a la palestra con una palabra de paz en los labios, muy compuestos, muy formales. Dijérase que un prematuro cansancio los domina y que no sienten entusiasmo ni aun por el aire que los agrupa" (González Castro, 1966: 188-199). La estética pacífica que defiende Cambours Ocampo recibió ya en su día numerosas enmiendas por parte de los críticos, quienes no entendieron en un principio si ese pacifismo contenía matices políticos o se trataba tan sólo de una propuesta estética (por otra parte, la difícil situación del momento inducía a pensar lo primero). Pero incluso los propios poetas novísimos se sintieron un tanto aturdidos ante la prédica de su mentor, pues aquellos anhelos pacifistas chocaban frontalmente con la tarea crítica que se imponen las vanguardias.

\section{LA CRÍTICA ANTE LA "NOVÍSIMA" GENERACIÓN. UNA POLÉMICA ENCENDIDA $^{6}$}

Un par de años después de publicarse Indagaciones sobre literatura argentina de Cambours Ocampo, Emilio Carilla (1954) da a conocer un breve ensayo que lleva por título Literatura argentina 1800-1950 (Esquema generacional), obra de carácter historicista que se vale de los planteamientos metodológicos

\footnotetext{
${ }^{5}$ Estas declaraciones pertenecen a una encuesta realizada a Cerretani para La Literatura Argentina, Buenos Aires, año III, No 34, junio de 1931, pp. 314.

${ }^{6}$ Un compendio de textos polémicos en torno a la generación de novísimos y a la anterior promoción de vanguardia - "primera generación de vanguardia"- se halla recogido en Cambours Ocampo (1987).
} 
de Petersen así como también de los esbozos generacionales, totales o parciales, ensayados por Julio V. González en 1916, Alberto Gerchunoff en 1939 y Manuel Mujica Láinez también en este último año. El "Esquema generacional" que formula Carilla es, expuesto de forma condensada, el que sigue:

La literatura argentina (lo que entra en esta denominación de letras gruesas) ofrece desde comienzos del pasado siglo una sucesión de diez generaciones [1810, 1821, 1837, 1853, 1866, 1880, 1896, 1910, 1924 y 1940]. Diez generaciones que -en las fechas propuestas- abarcan, cada una, un periodo aproximado de quince años (año más, año menos). Este eje de los quince años -a su vez- no se nos ha impuesto como una forzada aplicación de ideas de Ortega, sino que ha aparecido -creo- en la realidad móvil de nuestras letras (Carilla, 1954: 73).

Muchas son las discrepancias que plantea Cambours Ocampo respecto a la obra de Carilla, derivadas mayormente del excesivo número de generaciones que propone como posibles. Pero hay una queja fundamental que atañe especialmente a la labor de promoción y fijación que lleva a cabo el autor de La novísima poesía: la supresión de la generación de 1930, su generación. "El profesor Carilla inventa cuatro nuevas generaciones literarias argentinas: la 1821, 1853, 1866 y 1896. Y como se debe haber asustado por tantas generaciones lanzadas a voleo, suprime la de 1930" (Cambours Ocampo, 1963: 9-10). En el "Prólogo" a su libro, Carilla advertía no en vano de las dificultades crecientes a la hora de evaluar y fijar el conjunto de las generaciones que se suceden en el siglo XX, una problemática que en su opinión se agudiza aún más en el caso de las generaciones recientes (Carilla, 1954: 5). Así, por ejemplo, al tratar de forma concreta la "generación de 1940" señala: "La verdad es que aquí -con más razón que en otros productos espirituales- puede decirse que los árboles no dejan ver el bosque. Abundancia, proximidad y también -¿por qué no decirlo?- imprecisión desorientadora” (Carilla, 1954: 63).

No será Carilla el único historiador de la literatura nacional que obvie la existencia de la generación poética de novísimos al esbozar el trazado evolutivo de la poesía en la primera mitad del siglo XX. También Enrique Anderson Imbert recibe las quejas de Cambours Ocampo al no incluir a los novisimos en su Historia de la literatura hispanoamericana, cuya primera edición es de 1954, justo el mismo año en que Carilla publica su Esquema generacional. Anderson Imbert parte de cierta dificultad a la hora de distinguir entre la poesía publicada en torno a 1910 y la de aquellos que se erigen en portadores 
de una "nueva sensibilidad" (los vanguardistas). Entre otras cuestiones porque junto a los entusiastas de la nueva poesía "hubo excelentes poetas que crecieron como si el ultraísmo no existiera" (Anderson Imbert, 1961: 145). Tanto más dificultoso, afirma, resulta caracterizar la obra poética de aquellos otros que posteriormente hablaron de una "novísima sensibilidad" (146). En total desacuerdo con estos planteamientos, Cambours Ocampo (1963) rechaza igualmente "la falsa afirmación de que los escritores de 1930 se acercaron y se confundieron con los de la generación del 40" (39). Pues, en efecto, Anderson Imbert señala en su Historia que "los escritores del 30, al hacerse maduros, prefirieron acercarse a los más jóvenes". Y unas páginas más adelante aclara:

Los escritores nacidos alrededor de 1910, que aparecen en las letras hacia 1930, fueron mucho más moderados que los vanguardistas. Curados de espanto, buscaron el equilibrio. Habían conocido los extremos. Se propusieron ser más serios. Una filosofía más preocupada por conocer al hombre los condujo al viejo tema: la vida sentimental. Este neorromanticismo es el que acabará por hablar en voz alta en la generación siguiente, la de 1940 (Anderson Imbert, 1961: 204).

En opinión de Cambours Ocampo (1963) la verdadera razón de este solapamiento, que entiende intencionado, nada tiene que ver con un riguroso juicio crítico, ni siquiera con razones personales de índole estética ni política, sino más bien con un resentimiento generacional a la inversa (41). A favor de Anderson Imbert (1961) hay que señalar que, lejos de desmerecer los méritos de los poetas que dan a conocerse hacia 1930, hace hincapié en la necesidad de reconocer su valía: "Todo les interesaba. Nunca hubo en nuestra América un grupo tan bien informado sobre tan vastas actividades culturales como éste que apareció después de 1930" (1961: 147-148).

Ya sea por las amonestaciones que recibe de parte de Cambours Ocampo, quien lo acusa de "desertor" de su propia generación, o bien por un mayor distanciamiento de los hechos, o tal vez por ambas cosas, lo cierto es que en las diversas reediciones del tomo II de su Historia, sobre todo a partir de la aparecida en 1966 ( $5^{\mathrm{a}} \mathrm{ed}$.), Anderson Imbert retorna a las filas y rectifica algunas de sus opiniones, dotando de una mayor solidez histórica a la que, ahora sí, no duda en llamar "novísima generación" (Anderson Imbert, 1966: 223-224).

Otra de las disputas mantenidas por Cambours Ocampo con la crítica de su tiempo está co-protagonizada por uno de los escritores y ensayistas argentinos más relevantes de la segunda mitad del siglo XX: César Fernández Moreno, 
quien al decir de aquel "ha intentado la peregrina empresa de silenciar diez años de poesía nacional" (Cambours Ocampo, 1963: 51). En concreto se refiere a dos menciones directas a la novísima generación y a su propia persona como "inventor" de dicha generación a través de su antología del 31. La primera referencia aparece en el "Informe" de 1943 publicado en Nosotros. En él puede leerse: "Alrededor de 1930 comienza la disociación del grupo Martín Fierro; se acallan sus revistas, y sus integrantes, o se llaman a silencio, o publican aisladamente, separándose los mejores de ellos de las normas de la escuela y encauzando su personalidad por sendas propias. En 1931, Cambours Ocampo trata de arquitecturar una novísima generación, pero no es tarea fácil inventar poetas" (Fernández Moreno, 1943: 73). La respuesta de Cambours a estas palabras va a ser contundente, no exenta de desesperación por lo que entiende como una burla a la realidad literaria: "Es decir: alrededor de 1930 se disocia la nueva generación y, después, hasta 1940, la poesía argentina se convierte en una página en blanco. ¡Magnífico! Pero, ¿qué es esto? ¿Tontería, ignorancia o mala fe? ¿O las tres cosas juntas?” (Cambours Ocampo, 1963: 51).

La segunda referencia que rebate Cambours Ocampo es la aparecida en la Historia de Arrieta, en donde Fernández Moreno deshace una vez más la idea de una "generación novisima", estableciendo para ello un periodo de transición entre la primera vanguardia ("generación de 1922") y la "generación del 40" (para Fernández Moreno "generación del 35"), la de los poetas neorrománticos (Fernández Moreno, 1959: 612). Más que el hecho en sí de la postergación a la que se ven sometidos los novísimos (a la que, visto lo que llevamos, debía estar acostumbrado ya por entonces Cambours Ocampo), lo que realmente molesta a éste es que tal minusvalía acabe por instalarse de pleno en las historias literarias de ámbito nacional y continental, dado el carácter didáctico y neutral y el rigor que debería presidir este tipo de obras, y dada también, es evidente, su amplia capacidad de institucionalización del sistema literario. En lo que respecta a la historización de la poesía moderna que lleva a cabo Julio Noé, a decir verdad no menciona en ningún momento la existencia de una "generación del 30" como tal (menciona, eso sí, a algunos poetas que publican en la década de 1930), estableciéndose un vacío generacional entre la generación de 1922, de claro signo vanguardista, y la generación de 1940, los llamados "neorrománticos" (Noé, 1959: 125).

Apenas un año antes de la publicación del IV tomo de la Historia de Arrieta que incluye los citados trabajos de Fernández Moreno y Noé, publica Juan Pinto su Breviario, donde repite un esquema generacional poético similar al que proponen otros historiadores, saltando de la generación de 1922 a la del 40. Antes de ahondar en esta última se detiene en el comentario de La novísima 
poesía de Cambours Ocampo y en la posibilidad de que hubiese existido una generación de 1930. Su opinión puede resumirse en esta sentencia: "En realidad no hubo generación novísima, sino un grupo de escritores y poetas que intentó un movimiento, y que sólo dio frutos individuales. La generación de 1922 se hallaba en plena tarea, ordenando definitivamente el caos que había provocado con ímpetu renovador" (Pinto, 1958: 192).

En 1967 César Fernández Moreno da a conocer su ya clásico ensayo $L a$ realidad y los papeles, que lleva por subtítulo Panorama y muestra de la poesía argentina contemporánea. El análisis crítico abarca desde el modernismo hasta la generación del 50, previo repaso de las generaciones y periodos que al parecer del autor integran y definen la evolución de la poesía argentina. Fernández Moreno se reafirma en sus planteamientos de 1959 respecto a la división generacional y por tanto en lo que atañe a los novisimos, reproduciendo literalmente algunos fragmentos del capítulo redactado para la Historia de Arrieta. Hay que decir que cuando se da a conocer la primera edición de La realidad y los papeles Fernández Moreno es conocedor de las duras críticas que Cambours Ocampo le dedica en El problema de las generaciones literarias. La defensa que lleva a cabo Fernández Moreno de la inexistencia de una generación poética del 30 se basa fundamentalmente en la fecha de nacimiento de los autores; un dato puramente estadístico, numérico, que nos acerca a un estricto concepto de generación tal y como fue formulado en su día por la historiografía alemana. Hoy, pasadas algunas décadas de la enfermiza aplicación de este tipo de metodología y destapadas algunas invenciones -sin duda una de las más señaladas es la del 98 español, pero no la única-, leemos con rubor el siguiente párrafo:

Para aclarar toda confusión basta formar, con criterio ecléctico, un grupo de cincuenta poetas entre los de más ostensible actuación, nacidos en la Argentina entre 1890 y 1920 (...). Se observa entonces que 'el golpe de dados de la naturaleza' ha elegido en este lapso dos zonas de fechas de cuatro años la primera y de cinco la segunda, dentro de las cuales vio la luz la mitad más significativa de ese conjunto de poetas. Durante estos dos períodos nacen tres poetas por año, mientras en los otros veintidós sólo alcanza a nacer uno anual. ¿Qué significa esta desproporción al parecer azarosa? Será fácil determinarlo conociendo los nombres incluidos en esos dos periodos fértiles (Fernández Moreno, 1967: 224-225).

Sin duda es este un episodio de la historia de la poesía argentina aún sin cerrar, necesitado de aportes críticos significativos que arrojen nueva luz sobre los hechos con objeto de establecer unas conclusiones. Me he limitado tan sólo 
a exponer un cruce de opiniones en boca de aquellos que entonces participaron en la polémica y la consecuente repercusión de los hechos en la historia literaria nacional. Lo cierto es que, pese a señalar Arrieta que La novisima poesía argentina serviría de materia prima para futuras antologías, al menos por lo que se refiere a las publicadas en los años 30 y 40 los poetas compilados por Cambours Ocampo no serán tenidos en cuenta. Tan sólo veremos algún rescate de forma muy puntual, como es el caso del propio Cambours Ocampo y también de María de Villarino y Marcos Victoria, quienes aparecen recogidos en la Vidriera de la última poesía argentina de Andrés del Pozo (1937). A ellos debe sumarse la figura de José Portogalo, autor que aparece incluido en el Índice de la poesía argentina contemporánea de José González-Carbalho (1937).

\section{REFERENCIAS}

Aguilar, Enrique et al. (eds.). 1997. Ortega y la Argentina. Madrid/México: Fondo de Cultura Económica.

Anderson Imbert, Enrique. 1961. Historia de la literatura hispanoamericana. Vol II: "Época contemporánea”. México/Buenos Aires: Fondo de Cultura Económica. 1966. Historia de la literatura hispanoamericana. Vol II: "Época contemporánea". México/Buenos Aires: Fondo de Cultura Económica, $5^{\mathrm{a}}$ ed.

Arrieta, Rafael A. (ed.). 1958-1960. Historia de la literatura argentina. 6 vols. Buenos Aires: Peuser.

Arrom, José Juan. 1963. Esquema generacional de las letras hispanoamericanas. Bogotá: Instituto Caro y Cuervo.

Bioy Casares, Adolfo. 1940. La invención de Morel. Buenos Aires: Losada.

Cambours Ocampo, Arturo. 1931. La novísima poesia argentina. Buenos Aires: Letras.

1952. Indagaciones sobre literatura argentina. Buenos Aires: Albatros. 1957. Lugones. El escritor y su lenguaje. Buenos Aires: Theoría.

. 1963. El problema de las generaciones literarias. Buenos Aires: A. Peña Lillo.

_. 1987. Literatura y polémica. Discusiones con Enrique Anderson Imbert, Jorge Luis Borges, Emilio Carilla, César Fernández Moreno, Juan Carlos Ghiano y Roger Pla, con dos colofones y un apéndice para Federico García Lorca. Buenos Aires: Marymar.

Carilla, Emilio. 1954. Literatura argentina 1800-1950 (Esquema generacional). Tucumán: Universidad Nacional de Tucumán.

_. 1989. "El método generacional: posibilidades y limitaciones". En VV.AA. La periodización de la literatura argentina. Problemas, criterios, autores, textos. Vol I. Mendoza: Revista de Literaturas Modernas, pp. 69-82.

Del Pozo, Andrés. 1937. Vidriera de la última poesía argentina. Buenos Aires: Fragua.

Doll, Ramón. 1931. “Opina Ramón Doll”, en La Literatura Argentina 31, p. 13. 
Fernández Moreno, César. 1943. "Informe sobre la nueva poesía argentina”. Nosotros 91, pp. 71-93.

. 1959. "La poesía argentina de vanguardia". En Rafael A. Arrieta (ed.). Historia de la literatura argentina. Vol. IV. Buenos Aires: Peuser, pp. 605-669.

_. 1967. La realidad y los papeles. Panorama y muestra de la poesía argentina contemporánea. Madrid: Aguilar.

Giordano, Carlos. 1983. "Entre el 40 y el 50 en la poesía argentina", en Revista Iberoamericana 125, pp. 783-796.

González-Carbalho, José 1937. Indice de la poesía argentina contemporánea. Santiago de Chile: Ercilla.

González Castro, Augusto. 1966. Panoramas de las antologías argentinas. Buenos Aires: Francisco A. Colombo.

Lazo, Raimundo. 1954. La teoria de las generaciones y su aplicación al estudio histórico de la literatura cubana. La Habana: Universidad de La Habana.

Lewkowicz, Lidia F. 1974. Generación poética del 30. Buenos Aires: Ediciones Culturales Argentinas/Ministerio de Educación.

Marías, Julián. 1949. El método histórico de las generaciones. Madrid: Revista de Occidente.

Montaldo, Graciela. 1989. "Antologías (Polémicas)". En David Viñas (ed.). Historia social de la literatura argentina. Vol. VII: Yrigoyen, entre Borges y Arlt (19161930). Buenos Aires: Contrapunto, pp. 39-43.

Noé, Julio. 1959. "La poesía". En Rafael A. Arrieta (ed.). Historia de la literatura argentina. Vol. IV. Buenos Aires: Peuser, pp. 63-128.

Petersen, Julius. 1930. "Die Literarischen Generationen". En Ermatingen et al. Philosophie der Literatur Wissenschaft. Berlin: Junker und Dunnhaupt.

Pinto, Juan. 1958. Breviario de literatura argentina contemporánea. (Con una ojeada retrospectiva). Buenos Aires: La Mandrágora.

Portuondo, José Antonio. 1948. "Períodos y Generaciones en la historiografía literaria hispanoamericana”, en Cuadernos Americanos 3, pp.231-252.

Saitta, Sylvia. 1998. Regueros de tinta. El diario Crítica en la década de 1920. Buenos Aires: Sudamericana.

Salas, Horacio. 1968. La poesía de Buenos Aires. Ensayo y Antología. Buenos Aires: Pleamar.

Salazar Anglada, Aníbal. 2009. La poesía argentina en sus antologías, 1900-1950. Una reflexión sobre el canon nacional. Buenos Aires: Eudeba.

Thibaudet, Albert. 1936. Histoire de la littérature francaise de 1789 à nos jours (2 vols). París: Stock. 